\title{
Research on the construction of rural public sports service system in Sichuan province from the perspective of urban-rural integration
}

\author{
Hongying Li, Suqiong Feng*, and Liujie Yang \\ Chengdu Teaching Department, College of Physical Education, Sichuan Agricultural University, \\ Chengdu, China
}

\begin{abstract}
From the perspective of urban-rural integration, this paper analyzes the current situation of public sports service system in rural areas of Sichuan Province. In order to break through the dilemma of the Rural Public Sports Service System in Sichuan Province, we must seize the opportunity of the integration of urban and rural areas, conform to the regional characteristics of Sichuan, plan the steps of the supporting reform between urban and rural areas as well as the farmers' personal sports needs; and increase the farmers' economic income, meanwhile, we should introduce and attract social enterprises and social forces to invest a lot in the human, material and financial resources of rural public sports. Promoting the development of rural public sports service in Sichuan Province by optimizing the allocation of resources.
\end{abstract}

Keywords: Urban-rural integration perspective, Rural public sports, Service system.

\section{Introduction}

Rural public sports services are an important basis for improving the physical health of rural residents, and it is the general term for providing tangible or invisible sports products or services for the purpose of meeting the sports public needs of rural residents. The 19th National Congress of the rural revitalization strategy has brought new opportunities for the development of rural sports public services in China.

Despite the current reasons for multiple reasons, The overall development of public sports services in Sichuan Province lags behind, There are also problems such as supply subjects, backward shortage of infrastructure, capital guarantee, human resources guarantee and operation mechanism, In the new situation, How to seize the opportunity of urban-rural integration, Optimize the allocation through resources, With the regional characteristics of Sichuan, Coordinating the steps of urban and rural supporting reform and the personal sports needs of farmers; Follow by times, Taking measures according to local conditions, People oriented, Demand oriented, Focus on efficiency, Fair fairness, We will promote coordinated urban and rural development, We will promote rural public sports services with

\footnotetext{
*Corresponding author: 2476247436@qq.com
} 
rural, political, social, and cultural development as a whole, Common development, The real significance is to achieve the construction goal of "beautiful countryside".

\section{Factors influencing the rural public sports service system in Sichuan Province}

The development of physical education in rural schools also determines the key to the development of rural sports. In Sichuan Countryside School Physical Education Development is not balanced, the physical education teaching is more serious. Rural School Physical Education in rural areas has not been attached importance to and strengthened, physical education class random squeeze or sheep-like teaching there exist. Most pe teachers in rural schools are part-time teachers of other subjects. The school lacks the specialized sports talented person not to say the administrative village. Therefore, it leads to the situation that the rural sports in Sichuan Province can not realize the sustainable development, and it also leads to the imbalance of human resources guarantee of the rural public sports in Sichuan Province.

\subsection{The unbalanced economic development has great differences in sports ideology}

Sichuan is a very complex landform province, the terrain is very diverse, with mountains, plateau, grassland, hills, plains. Therefore, the rural areas of Sichuan Province are divided into different areas such as mountain, Panxi, hilly, Chengdu Plain, western Sichuan Plateau and other regions. The population of Sichuan is mainly rural population, with more population distribution in the east than the west and more plains and hills than the mountainous plateau. However, another important feature of Sichuan has 51 ethnic groups such as Han, Yi, Tibetan, Qiang and Hui, and is one of the multi-ethnic provinces and regions in China. Rural population, land and economic development indexes of cities and states show good natural resources and geographical conditions, developed transportation and certain tilt in capital and policy, so their rural population, land and economic development index are high. In recent years, rural land and economic development in southern Sichuan have developed rapidly in recent years. Rural population and land development in the hilly area of northeast Sichuan is relatively weak. The Northwest Sichuan Plateau region and Panxi region are affected by natural and geographical location, and the rural population, land and economic development indexes themselves are not high. The regional economic imbalance will involve local educational resources. The poverty of educational resources leads to the lack of the concept of rural population sports, weak awareness of mass sports and backward health concept. In addition, with the physical overdraft of rural people and the lack of sports knowledge, physical activities will be excluded from their daily life. Although rural sports activities have always been paid attention to by local governments, due to the large gap between physical education level and physical awareness between the rich and the poor in Sichuan Province, especially in remote areas (especially in Yi areas and Tibetan areas) are relatively weak.

\subsection{Unbalanced distribution of rural public sports infrastructure in Sichuan Province}

Sichuan Provincial Sports Bureau has always taken strengthening the construction of sports infrastructure as a key task to grasp, In the first half of 2020,104 million yuan of central and provincial funds was invested in the construction of 9,254 village-level sports and fitness 
facilities for farmers in the province, Equipment bidding for 3,888 projects has been completed in advance, Early completion and acceptance of 467 projects; The central and provincial funds were invested at 32.5 million yuan, We supported the construction of 45 township fitness centers, urban community fitness centers, and urban sports parks, Yi new Village 100 construction projects; By the end of 2019, The provincial sports venues are 238,400 , The stadium site covers an area of 127 million square meters, The per capita stadium ground area is 1.52 square meters.Although the Sichuan Provincial government has made more and more strong investment and construction in rural public sports infrastructure, the vast majority of rural public sports facilities have also been significantly improved. However, due to the influence of topography, landform, transportation, population and cultural quality of Sichuan Province, the level of sports infrastructure construction is limited to a certain extent, and the reality gap in establishing rural public sports service system in urban and rural areas exists. For example, as of 2019, the stadium area of Dongpo District of Meishan City is 1.54 million square meters, per capita stadium area of 1.84 square meters; Liangshan Prefecture has a stadium area: 482.8044 square meters, per capita stadium area: 0.86 square meters. In a township in Tibetan areas shows that the township government has an outdoor standard cement basketball court, mainly for grass-roots cadres and young people around the township. Village-level outdoor equipped with simple fitness equipment; indoor equipped with basketball, rope skipping, badminton and other basic sports equipment, but the utilization rate is extremely low. It can be seen from the survey data that the imbalance of rural economy and the regional gap also show the imbalance of rural public sports infrastructure.

\subsection{Unbalanced fund guarantee for rural public sports in Sichuan Province}

Under the guidance of the rural revitalization strategy, the government has allocated sports funds for the cause of rural sports construction. But in general, rural sports funds are less than urban sports funds. Due to the rural gap in sichuan province, in the plain area due to the developed traffic, people change fitness concept, widely mobilize the masses and society from all walks of life actively participate in the inheritance and development of sports culture, many enterprises and individuals will actively invest in sports while sports lottery public welfare fund also used for national fitness special site construction, national fitness equipment update such as grassroots sports activities and facilities construction. This provides the maximum financial guarantee for public sports construction; it is difficult to attract enterprises and individuals in some rural mountains and remote ethnic minorities to invest in sports. Combined with the infrastructure invested by the government with low utilization rate and lack of daily maintenance, while local governments cannot provide more financial funds to invest in rural sports due to their economic problems, so government finance alone cannot guarantee rural public sports funds.

\subsection{Unbalanced human resources guarantee of rural public sports in Sichuan Province}

The towns around Chengdu, Sichuan province, have leading groups in charge of sports, full-time social sports instructors and special sports funds. Farmers in each township personally participated in the farmers' sports games or fitness activities. However, due to the economic imbalance, there are many remote town (township) governments and village level in Sichuan Province that do not have special sports fund investment, and no special leaders in charge of sports work. Their leadership mainly focuses on economic construction. Many grass-roots leaders believe that sports cannot not solve the problems of food and clothing, employment and prosperity. There were no sports activities in the remote 
mountainous areas, and the farmers' games were held only in the local cities (continents). The vast majority of administrative villages have not organized sports competitions or fitness activities in their villages. To this end, we investigated Xiaba Township in a Tibetan area, which is located in Feixi District, Kangding City, Ganzi Tibetan Autonomous Prefecture, Sichuan Province, close to Xinduqiao Town, "Photography Paradise". Its area is 460 square kilometers, and has jurisdiction of 11 administrative villages with a total population of 3,835 people with an average altitude of more than 3,500 meters, which belongs to the typical Kangba Tibetan area. At present, a township level deputy leader and a staff member is responsible for the township cultural and sports work, mainly engaged in the personnel organization of sports activities arranged at the county level, and the statistical distribution of sports equipment. . They believe that the lack of professional sports at the township level. In addition, the development of physical education in rural schools also determines the key to the development of rural sports. Physical education development in Sichuan rural schools is unbalanced, and physical education teaching is more serious. Sports work in rural schools has not been paid attention to and strengthened, and physical education class randomly crowded or sheep teaching. Most physical education teachers in rural schools are part-time teachers in other subjects. Schools lack professional sports talents, let alone administrative villages. Therefore, this leads to the situation of the sustainable development of rural sports in Sichuan Province, and also leads to the unbalanced human resource guarantee of rural public sports in Sichuan Province.

\section{Development path of rural public sports service in Sichuan Province}

The study of rural public sports services not only only noticed the imbalance of rural economic development, cultural differences, should also analyze the geographical environment, mode of production, way of life, way of thinking, values, cultural consciousness and management system and other social change factors, these factors are the source of village sports survival and soil. For the construction of the rural public sports service system, Should comply with the regional characteristics, Coordinating the steps of urban and rural supporting reform and the personal sports needs of farmers; The public sports services provided need to follow from time to time, Taking measures according to local conditions, People oriented, Demand oriented, Focus on efficiency, Fair fairness, Government-led, Multiple participation, Overall coordination, The reality of the two places, Due to the reality of the regional gap, Establish a public sports service system covering the vast rural areas, It is impossible to take a chess game of chess, One-size-fits-all approach, A pattern of the way to the, There is a specific implementation path problem, Should be based on the regional characteristics, Seek an equilibrium point between fairness and efficiency.

\subsection{Strive to create a national fitness atmosphere and enhance the awareness of national sports ideology}

First of all, we should greatly improve the level of rural network facilities, All village should pass through relevant government staff, village cadres, schools, television and other channels, Further strengthen the publicity of sports and fitness, Popularize scientific fitness knowledge, Publicize the sports and fitness culture, Promote the new concept of health, Advocate a healthy and civilized lifestyle, Strive to create a social atmosphere of the whole village national fitness; Thirdly, governments and departments at all levels should take the development of mass sports as a long-term guiding ideology in formulating local sports regulations and policies for the masses, The actual situation of the local rural areas and the 
practical needs of the farmers should be considered; More sports activities should be held in the village, While combining the sports characteristics of the village and innovating the sports folk culture of the village, In this way can we attract more villagers to actively participate in it, To let the local villagers truly experience the fun that sports brings to them, To truly improve their sports ideology.

\subsection{Continue to step up efforts to build rural public sports infrastructure}

The Sichuan Provincial government has taken measures to local conditions and has built a number of national fitness centers, fitness trails, sports parks and other fitness facilities around the public and community fitness centers, and the people's fitness conditions have been greatly improved. However, due to the large investment in infrastructure and the basic constraints of large population, weak foundation, underdeveloped and imbalance in Sichuan Province, the construction level of sports infrastructure construction around the masses is lower than the national average level. To this end, Sichuan Provincial Sports Bureau in the "14th Five-Year Plan" put forward: continue to increase the construction of sports facilities. We should not only take into account the actual needs of rural residents in production and life, but also allocate infrastructure resources according to the scale of factors such as industrial integrated development. Sports facilities planning should be incorporated into the village planning, land planning, make full use of rural green space, mountains to build small, simple, convenient people, various forms of grassroots sports facilities; according to local conditions, teach students, create rural characteristic sports, carry out some rich and diverse leisure sports projects. We will build important support and infrastructure for managing rural public infrastructure and implementing the rural revitalization strategy.

\subsection{Constantly improve the special fund system for sports development, integrate sports industry resources, and guarantee sports funds}

In order to ensure that the rural sports funds are guaranteed, the funds for sports activities must be included in the financial budget. Especially for the economically poor administrative villages should be given certain subsidies. When the financial strength of the government cannot be met, local governments explore ways to attract extensive participation through government and private capital and loan discount interest, guide industrial and commercial capital and financial capital to actively undertake government service supply functions, and increase financial investment. At the same time, the administrative village makes use of the national characteristics and unique geographical features to attract more social enterprises to invest in some sports events, sports tourism, rural leisure and vacation and home stay and other emerging industries. For the enterprises that support the development of the sports industry, we should introduce some preferential policies to increase the support for enterprises. This has boosted the development and expansion of the province's rural sports industry. In the real sense, we will achieve win-win results for the government, social capital and rural residents.

\subsection{Cultivate rural social sports instructors and sports management talents through multiple ways}

First of all, the township government (administrative villages) should deal with the special sports work leading group, to have a special in charge of sports rural grass-roots sports cadres and officers. And require how many times a year in the village farmers and rural activities of the hard index. At the same time, we should be targeted and strengthen efforts to train social sports instructors in line with the village, and sign rural sports practice bases 
for college students with some local universities and sports colleges. County-level sports associations should be regularly invited to support them to the countryside. The government should give certain policy support to the instructors and managers participating in supporting rural sports. Only by training social sports instructors at all levels can we improve the physical quality of the people in the province. Only we can realize the integration of urban and rural areas in the real sense, realize the integration of rural sports resources, and realize the sharing of human, material, financial resources and information.

\section{References}

1. Lu Wenyun, Research on the current situation, problems and countermeasures of the supply of public sports services in rural western areas under the background of new rural construction [J], Sports Science, 2010,30 (2): 11-19

2. Xu Caiming et al., Research on the Upgrade Route of Rural Sports Public Service in China under the background of "Rural Revitalization Strategy" [J], Journal of Xi'an College of Physical Education, 2017,9:555-561

3. Shu Gangmin, the governance path of rural sports public service supply in China [J], Chengdu Institute of Physical Education, 2017,43 (5): 33-39

4. Chen Xinlin, Research on the imbalance of public sports resources allocation and reform orientation in rural areas of China under the Vision of Urban-rural Integration [J], Agricultural Economy, 2018.9:96-98

5. Zhu Mengbin, on the difference of public sports service between urban and rural areas under the overall background--Taking Beibei district of Chongqing as an example [ $\mathrm{j}]$, contemporary science and Technology 2015(25)155-156 